\title{
$\mathrm{E} \cdot \mathrm{D} \cdot \mathrm{I} \cdot \mathrm{T} \cdot \mathrm{O} \cdot \mathrm{R} \cdot \mathrm{I} \cdot \mathrm{A} \cdot \mathrm{L}$
}

\section{What Is Practical Failure Analysis?}

T

he birth of Practical Failure Analysis is the result of the efforts of a large number of people - people with a vision and with expectations for the periodical's success. Hopefully, this first issue meets those expectations and is the first step toward fulfilling the vision. Several people have asked, "What is the ultimate goal of the publication and what constitutes practical failure analysis?" The goal is for the publication to be of value to the failure analysis community. Defining practical failure analysis is, however, challenging. Practical, like beauty, is frequently in the mind of the beholder and changes over time.

Forty years ago, the American Society for Metals provided copies of a 12-year old book to each of the metallurgical engineering graduates in the Class of 1960 at Virginia Polytechnic Institute. The 1948 Edition of the Metals Handbook has had a special place on my bookshelf since that time. The Handbook discusses the basic causes of failure by stating "if it is assumed that a proper selection of metals has been made - and this is a reasonable premise, in view of the immense amount of data given elsewhere in the Handbook, concerning chemical composition and mechanical properties - then the causes of failure of metals in service may be grouped into three categories: design factors, processing, and service environment."

In June of last year, Mr. Robert Johnson, a Life Member of ASM International, contributed to Practical Failure Analysis, a collection of photographs of equipment failures that he had investigated while working at the Canton and Massillon, Ohio plants of Republic Steel from 1942 through 1953. Mr. Johnson also contributed copies of several journal articles that reviewed his analysis of those failures. A 1961 Republic Steel Corporation booklet "Analysis of Service Failures" was included in the package. This booklet stated that "through years of study, testing, and research, the common conditions which may lead to failure have been identified. The fundamental factors affecting service life are: 1 . Design, 2. Steel selection, 3. Heat treatment, 4. Material quality, 5. Method of fabrication, and 6. Assembly. Service failures as well as those during fabrication may be related to any one or combination of the above factors."

A working definition of practical may be found from two observations involving the handbook, the booklet, and modern failure analysis techniques. These observations are: 1) the assumption in the 1948 Edition of the Metals Handbook that proper materials selection was routine significantly contrasts the 1961 listing of materials selection as a fundamental cause of failure, and 2) neither the handbook nor booklet made any reference to using a scanning electron microscope in any portion of a failure analysis even though the SEM is a standard part of the modern failure analyst's toolbox.

The first observation illustrates that confirmation, rather than assumption, is a practical key to any failure analysis. The second observation illustrates the ever-changing nature of practical approaches to the analysis of failures. New analytical tools are continually emerging and must be evaluated for application to the failure analysis process. This was also apparent from another paper, "A Review of Some Mechanical Failures of Steel Plant Machine Equipment," Society for Experimental Stress Analysis, Vol. III, No. 2, p.61-75, 1946, included in the package sent by Mr. Johnson. In that paper, S. W. Poole and R. J. Johnson stated, "as a sidelight to the discussion of the previous failure, the authors consider it timely to call attention to use of supersonic methods for detecting internal ruptures in heavy forgings." Clearly, the identification of new tools, techniques, and equipment has been part of practical failure analysis for a long time.

Today, Practical Failure Analysis is a beginning. It is my vision that this periodical will become a resource to the failure analyst, to the metallurgist, and to anyone wanting to understand component failure and failure prevention methodologies. Fulfillment of this vision is up to you. Success requires the continual publication of quality manuscripts - manuscripts that describe work you have done, understanding you have gained, and equipment/processes you have developed.

What is Practical Failure Analysis? Ultimately it will be what you, the reader, want and are willing to contribute toward its success. Many of you, like Mr. Johnson, have used failure analysis as a building block for your career. Are you willing to share some of your building blocks? The future of Practical Failure Analysis is dependent on such sharing.

I'm looking forward to hearing from you in the near future.

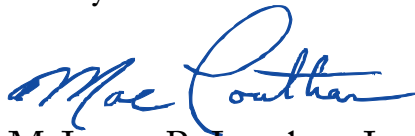

McIntyre R. Louthan, Jr.

Editor

(tel: 803/725-5772; e-mail: mcintyre.louthan@srs.gov)

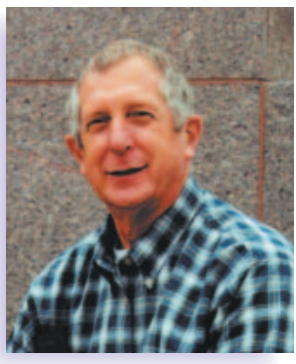

